\title{
DETERMINANTE NEEKONOMIČNOSTI ZAPOSLENIH U DOMOVIMA ZDRAVLJA U REPUBLICI SRPSKOJ
}

\section{Bojan Kresojević ${ }^{1}$}

\author{
${ }^{1}$ Ekonomski fakultet \\ Univerziteta u Banjoj Luci
}

\section{Correspondence:}

Bojan Kresojević

e-mail:

bojankresojevic@outlook.com

\section{Rezime:}

U skladu sa trendom produžavanja životnog vijeka stanovništva, smanjenja stope nataliteta, i sve izraženijim problemima finansiranja zdravstvene zaštite u Republici Srpskoj, pitanje (ne)ekonomičnosti zaposlenih u zdravstvenim ustanovama postaje sve interesantnije. Posmatrajući 53 doma zdravlja u Republici Srpskoj, uočeno je da učešće troškova ličnih primanja varira od $37,3 \%$ do $109,4 \%$ prihoda u 2015. godini, pri čemu je neponderisani prosjek $82,2 \%$. Ovi nalazi postavljaju izazov iznalaženja determinanti stepena i varijabiliteta neekonomičnosti zaposlenih u domovima zdravlja u Republici Srpskoj. Prilikom istraživanja, kao izvori korišteni su podaci iz finansijskih izvještaja domova zdravlja, kao i podaci o broju registrovanih lica u domovima zdravlja. Utvrđivanje determinanti sprovođeno je uz pomoć višestruke linearne regresione analize, na osnovu prethodnog prilagođavanja izvora podataka, koji su pretvoreni u izvjesne racio brojeve. Analiza je pokazala da su statistički značajne tri determinante, sa ukupnim objašnjenim varijabilitetom od $87,3 \%$, odnosno broj zaposlenih (47,1\%), lična primanja po zaposlenom (15\%) i prihod doma zdravlja (30,6\%). S obzirom na to da je broj zaposlenih najznačajniji uzrok neekonomičnosti, nastavak analize usmjeren je na određivanje kriterijuma optimalnog broja zaposlenih. Optimalan broj zaposlenih određen je uz pomoć logaritamske regresione analize, pri čemu je broj registrovanih lica regresor. Svođenjem na optimalan broj zaposlenih bila bi oslobođena sredstva od 11,2 miliona KM.

\section{Ključne reči:}

višak zaposlenih, optimalni broj zaposlenih, oslobođena sredstva, višestruka linearna regresija, prosta logaritamska regresija.

\section{UVOD}

Značaj upravljanja troškovima u zdravstvenom sektoru nikad nije bio veći, istorijski posmatrano. Starenje stanovništva, konstantan rast cijena lijekova i stagnacija prihoda su ključne determinante oskudnosti sredstava u zdravstvenom sistemu. Situacija nije ništa drugačija kada se posmatra primarna zdravstvena zaštišta, koju između ostalog provode domovi zdravlja. Gorenavedene determinante negativno utiču na primarnu zdravstvenu zaštitu kroz povećan broj posjeta, više troškove lijekova na teret domova zdravlja, manjeg dijela sredstava koji se izdvaja za primarnu zdravstvenu zaštitu i to zbog povećanih troškova sekundarne i tercijalne zdravstvene zaštite. Domovi zdravlja su javne zdravstvene ustanove koje posluju kao neprofitne organizacije, sa ciljem pružanja zdravstvene 
zaštite stanovništvu. Kako bi zdravstvena zaštita bila na zadovoljavajućem nivou u dugom roku, neophodno je da poslovanje domova zdravlja bude održivo. Održivo poslovanje postiže se kada su prihodi domova zdravlja veći od ukupnih rashoda. Troškovi ličnih primanja su najveća stavka troškova u zdravstvenom sistemu, stoga je potrebno pratiti njihovo kretanje sa posebnom pažnjom.

Problem ovog istraživanja su visoki troškovi ličnih primanja u domovima zdravlja u Republici Srpskoj. Visoki troškovi ličnih primanja, dovode do visokih ukupnih troškova i neekonomičnog poslovanja. Rezultat se ogleda u otežanom finansiranju primarne zdravstvene zaštite.

Predmet ovog rada je ekonometrijska analiza determinanti neekonomičnosti zaposlenih, odnosno visokog učešća troškova ličnih primanja u prihodu domova zdravlja u Republici Srpskoj. Vremenski obuhvat istraživanja je 2015. godina.

Naučni cilj ovog istraživanja jeste otkrivanje determinanti neekonomičnog poslovanja zdravlja u Republici Srpskoj, uz pomoć višestrukog regresionog modela. Pragmatični cilj istraživanja je davanje smjernica rukovodstvu domova zdravlja u pogledu rješavanja problema visokog učešća troškova ličnih primanja u prihodu.

Polazna hipoteza ovog istraživanja je da broj (višak) zaposlenih, lična primanja po zaposlenom, i visina prihoda doma zdravlja predstavljaju ključne determinante visokog učešća troškova ličnih primanja u prihodu.

U radu će biti testirana polazna hipoteza uz pomoć višestruke linearne regresije, a zatim će biti date preporučene vrijednosti za broj zaposlenih u domovima zdravlja. Nakon toga, biće dati potencijalni efekti uštede, u slučaju da se broj zaposlenih svede na preporučene vrijednosti.

\section{TEORIJSKI OKVIR}

Domovi zdravlja predstavljaju javne zdravstvene ustanove koje se organizuju na teritoriji jedne ili više opština. U Republici Srpskoj postoji 53 doma zdravlja. U domovima zdravlja se obavljaju usluge po modelu porodične medicine. Djelatnost domova zdravlja spada u primarni nivo zdravstvene zaštite. Osnivači domova zdravlja razmatraju izvještaje o poslovanju i biraju rukovodstvo. Osnivači domova zdravlja su opštine u Republici Srpskoj [1]. Najznačajniji prihodi doma zdravlja su: doznaka od Fonda zdravstvenog osiguranja Republike Srpske, participacija osiguranika i prihod od neosiguranih lica. Doznaka od Fonda zdravstvenog osiguranja određuje se na osnovu [2]:
- Cijene tima u odnosu na standard (prim. aut. korigovane za odnos broja registrovanih lica i broja registrovanih lica po standardu);

- Opšte kapitacije i koeficijenta težinske kapitacije.

Opšta kapitacija je iznos sredstava koji odgovara težinskom koeficijentu 1. Težinski koeficijenti kapitacije predstavljaju relativne vrijednosti sredstava koja se odobravaju za svako registrovano lice u domu zdravlja. Težinski koeficijenti su različiti za svaki dom zdravlja, zbog različite starosne strukture registrovanih pacijenata. Ovdje je pretpostavka da lica različite starosne grupe uzrokuju različite vrijednosti troškova. Ukupni težinski koeficijent, koji se množi sa visinom opšte kapitacije, dobije se kao prosjek težinskih koeficijenata za svaku starosnu grupu, pri čemu se ponderisanje vrši brojem registrovanih lica u svakoj starosnoj grupi. Pored navedenog, Fond zdravstvenog osiguranja doznačava sredstva po osnovu nerazvijenosti određenih opština. Kao što se može vidjeti, prihodi domova zdravlja su pod relativno malim uticajem domova zdravlja.

Rashode domova zdravlja čine: troškovi ličnih primanja, troškovi lijekova, troškovi sanitetskog materijala, troškovi amortizacije i rezervisanja, troškovi energije, troškovi zakupa i sl. Troškovi ličnih primanja obuhvataju troškove bruto zarada, troškove bolovanja do 30 dana, troškove novčanih naknada i nagrada, troškove prevoza i sl. Broj zaposlenih u domovima zdravlja je normiran [3]. Tako je određeno da na svakih 2.000 registrovanih lica u domu zdravlja odgovara 1 porodični ljekar, 0,5 medicinskih sestara sa visokom stručnom spremom i 1,5 medicinskih sestara sa srednjom stručnom spremom. Ono što otežava primjenu standarda i normativa, kada je u pitanju broj zaposlenih u domovima zdravlja, jeste usitnjena struktura mreže domova zdravlja u Republici Srpskoj. Mrežu domova zdravlja čini 53 doma zdravlja, od kojih najmanji ima 891 registrovano lice, a najveći 189.460 registrovanih lica. Čak 5 domova zdravlja imaju manje od 2.000 registrovanih lica, a 9 domova zdravlja ima manje od 4.000 registrovanih lica. S obzirom na to da se radi o domovima zdravlja koji nisu u neposrednoj blizini, često se dešava da nije moguće zaposliti radnike $\mathrm{u}$ više domova zdravlja kako bi ispunili normu, već se u cjelosti zapošljavaju u jedan dom zdravlja i na taj način se zapošljava više radnika u odnosu na broj koji propisuje standard.

Poslovanje zdravstvenih ustanova do sada je vrlo malo bilo predmet izučavanja akademske javnosti u Republici Srpskoj. Na svjetskom nivou ovo je veoma aktuelno pitanje zbog narastajućih troškova zdravstvene zaštite, koji rastu brže od bruto domaćeg proizvoda. Na važnost 
efikasnog upravljanja resursima u zdravstvenoj zaštiti ukazuju i stavovi autora koji smatraju da se u zdravstvenom sistemu Sjedinjenih Američkih Država troši 700 milijardi dolara, koji ne doprinose poboljšanju izlaza (engl. outcome) sistema zdravstvene zaštite [4]. U svjetskoj nauci i praksi pažnja se sve više poklanja mjerenju performansi. Tako je u prethodnih 25 godina došlo do suštinskog razvoja mjerenja performansi, radi obezbjeđivanja poboljšanja zdravstvenog sistema [5]. U literaturi se mogu pronaći različite strategije snižavanja troškova zaposlenih u domovima zdravlja. Jedna od strategija za rješavanje ovog problema u Velikoj Britaniji odnosila se na obučavanje zaposlenih [6].

\section{METODOLOGIJA ISTRAŽIVANJA}

Analiza je zasnovana na podacima iz finansijskih izvještaja domova zdravlja u Republici Srpskoj za 2015. godinu. Određene stavke finansijskih izvještaja stavljane su u međusobni odnos, kao i u odnos sa brojem registrovanih lica, te su tako dobijeni racio brojevi predstavljali osnovu za kvantitativnu analizu međuzavisnosti.

\section{Varijable i indikatori}

Zavisna varijabla u ovom istraživanja su troškovi ličnih primanja domova zdravlja u Republici Srpskoj. Nezavisne varijable su: broj (višak) zaposlenih, lična primanja po zaposlenom i prihod doma zdravlja.

Kako bi troškovi ličnih primanja bili uporedivi, stavljeni su u odnos sa ukupnim ostvarenim prihodom, i na taj način se dobije učešće troškova ličnih primanja u prihodu. Prva nezavisna varijabla broj zaposlenih je mjerena brojem zaposlenih na 100 registrovanih lica doma zdravlja, koji se poredi sa preporučenom vrijednošću za određeni dom zdravlja. Troškovi ličnih primanja po zaposlenom mjereni su prosječnim izdacima za lična primanja (bruto plate, naknade za bolovanja do 30 dana, novčana pomoć i sl.) po zaposlenom. Prihod doma zdravlja mjeren je prihodom po registrovanom licu, kako bi se postigla uporedivost između domova zdravlja.

\section{Metod i podaci}

Kao metod za utvrđivanje relevantnih faktora, koji određuju visinu učešća troškova ličnih primanja u prihodu, korišćena je višestruka linearna regresiona analiza. Uzorkom su obuhvaćena 53 doma zdravlja, što predstavlja izuzetno dobar uzorak u pogledu veličine. Izvori podataka o prihodima, rashodima i broju zaposlenih domova zdravlja prikupljeni su iz finansijskih izvještaja domova zdravlja. Podaci o broju registrovanih lica u domovima zdravlja su podaci Fonda zdravstvenog osiguranja Republike Srpske.

Regresija predstavlja metod za utvrđivanje matematičke funkcije između zavisne i nezavisnih varijabli. Utvrđivanje funkcije vrši se tako da se izračunavaju parametri, tako da se postiglo minimalno odstupanje podataka od regresione krive. Klasični višestruki linearni regresioni model koristi se nakon što se testiranjem utvrdi da nijedna nezavisna varijabla ne objašnjava varijacije u zavisnoj mjeri u dovoljnoj mjeri. Opšti oblik višestrukog linearnog regresionog modela može se predstaviti na sljedeći način [7]:

$$
Y=\beta_{O}+\beta_{1} X_{1}+\beta_{2} X_{2}+\cdots+\beta_{k-1} x_{k-1}+\varepsilon
$$

Gdje je: $\mathrm{Y}$ zavisna promjenljiva, $\mathrm{X}_{1}, \mathrm{X}_{2}, \ldots, \mathrm{X}_{\mathrm{k}-1}$ su nezavisne varijable, a $\varepsilon$ predstavlja varijacije koje nisu objašnjene nezavisnim varijablama u modelu. Parametar $\beta_{0}$ pokazuje vrijednost koju uzima zavisna varijabla $Y$ kada su vrijednosti $X_{1}, X_{2}, \ldots, X_{k-1}$ jednake 0. Parametri $\beta_{1}, \beta_{2}, \ldots, \beta_{k-1}$ pokazuju promjenu zavisne varijable $Y$ kada se odgovarajuća varijabla poveća za 1 mjernu jedinicu.

U jednačini je (2) prikazan model sa (k-1) nezavisnih, objašnjavajućih varijabli. Navedena relacija odnosi se na potpuni obuhvat vrijednosti koje varijable mogu uzeti, drugim riječima radi se o relaciji koja važi za statistički skup. Metodom najmanjih kvadrata izračunava se matematička relacija na osnovu empirijski prikupljenih podataka. Empirijski prikupljeni podaci su, po pravilu, ograničenog broja i radi se na uzorku. Zato se prvobitno izračunava linearna jednačina koja opisuje matematičku relaciju između zavisne varijable i nezavisnih varijabli, ali na osnovu podataka iz uzorka.

$$
Y_{i}=b_{o}+b_{1} x_{1, i}+b_{2} x_{2, i}+\cdots+b_{k-1, i} X_{k-1}+\varepsilon_{i}
$$

Parametri su označeni malim latiničnim slovom (b) umjesto velikim grčkim slovom ( $\beta$ ), jer se radi o vrijednostima koje su dobijene na osnovu podataka iz uzorka. Ovako dobijeni parametri se testiraju. Polazna hipoteza za svaki parametar jeste da je on jednak nuli. Testiranje se vrši tako što se uz pomoć t-testa izračunava $p$ vrijednost koja pokazuje vjerovatnoću da je parametar jednak 0 , odnosno da nije statistički značajan.

Prvobitno je nekoliko varijabli testirano u modelu kao faktora koji potencijalno određuju visinu učešća troškova ličnih primanja, a kriterijum za prihvatanje modela je 
visok stepen objašnjenosti varijabiliteta u zavisnoj varijabli (učešće troškova ličnih primanja u prihodu), sa varijabilitetom nezavisnih varijabli $\left(\mathrm{r}^{2}-\right.$ koeficijent determinacije). Drugim riječima, uslov za prihvatanje modela je visok stepen podudarnosti empirijskih i vrijednosti dobijenih po modelu. Visok stepen podudarnosti empirijskih i vrijednosti po modelu govori da je obuhvaćen dovoljan broj varijabli koje ostvaruju značajan uticaj na zavisnu varijablu. Uz pomoć $p$ vrijednosti koeficijenata nagiba nezavisnih varijabli (regresora) moguće je provjeriti da li je data varijabla potrebna u modelu, tj. da li postoje varijable koje su nepotrebne u modelu. Odnosno, sve varijable sa $p$ vrijednošću preko 0,05 isključene su iz konačnog modela.

Na osnovu regresionog modela u kojem su sve varijable iskazane u sopstvenim jedinicama mjere, nije moguće zaključiti koja varijabla ostvaruje najznačajniji uticaj i to iz razloga što stepen varijacije (mjeren standardnom devijacijom) nije jednak kod svih varijabli, te dobijene koeficijente nagiba nije moguće međusobno upoređivati. Ovaj problem je prevaziđen izračunavanjem standardizovanog odstupanja po formuli:

$$
z=\frac{x-\mu}{\sigma}
$$

\section{Pri čemu su:}

$\mathrm{x}$ - originalna vrijednost varijable,

$\mu$ - aritmetička sredina i

$\sigma$ - standardna devijacija.

Standardizovanim odstupanjem izolovan je efekat različitog stepena varijacija. Nakon toga, bilo je moguće ponovo primjeniti višestruki linearni model na transformisanim podacima. Ovako dobijeni koeficijenti nagiba (uticaja) pojedinačnih varijabli su uporedivi.

Relativni uticaj pojedinačne nezavisne varijable po modelu može se dobiti dijeljenjem apsolutne vrijednosti koeficijenta nagiba sa zbirom apsolutnih vrijednosti svih koeficijenata nagiba. Ovako dobijeni relativni uticaj predstavlja procenat uticaja pojedinačnog faktora u odnosu na uticaj faktora koji su obuhvaćeni modelom (pritom ne uzimajući u obzir faktore koji nisu obuhvaćeni modelom). Zbog toga su, naposlijetku, koeficijenti relativnog uticaja pomnoženi (korigovani) sa ukupnim stepenom objašnjenog varijabiliteta (koeficijentom determinacije).

Nakon toga, prostim regresionim modelom testiran je uticaj broja registrovanih lica na stopu zaposlenosti. S obzirom na to da je početna pretpostavka da se stopa zaposlenosti smanjuje sa povećanjem broja registrovanih lica, a da nije realno da je smanjenje proporcionalno (linearno), testirani su i drugi modeli proste regresione analize, pored najčešće korišćene proste linearne regresione analize. Utvrđeno je da je najviši stepen slaganja kod logaritamskog regresionog modela.

Logaritamski regresioni model pokazuje prosječne vrijednosti stope zaposlenosti pri datom broju registrovanih lica u domu zdravlja. Ovo je urađeno sa ciljem da se domovi zdravlja porede sa sebi sličnim domovima zdravlja u pogledu veličine. Nakon toga, vrijednosti dobijene modelom određene su kao gornje granice prihvatljive visine stope zaposlenosti, što znači da se sve vrijednosti iznad toga mogu smatrati neopravdano visokom stopom zaposlenosti.

Nakon toga, za sve domove zdravlja kod kojih je stopa zaposlenosti iznad dobijenih vrijednosti po modelu, preporučuje se vrijednost koja je dobijena po modelu. Tako dobijene vrijednosti stope zaposlenosti mogu se uvrstiti $\mathrm{u}$ višestruki regresioni model i dobiti učešće troškova ličnih primanja u prihodu, kada bi domovi zdravlja uvažili preporuku da stopu zaposlenosti smanje na preporučenu visinu. Kada se od ovako izračunatog učešća troškova ličnih primanja u prihodu oduzme učešće troškova ličnih primanja dobijena višestrukim linearnim regresionim modelom sa stvarnom stopom zaposlenosti, dobije se potencijalna ušteda doma zdravlja u procentima prihoda. Na taj način moguće je izračunati potencijalno smanjenje doznaka Fonda zdravstvenog osiguranja Republike Srpske domovima zdravlja koji su smanjili troškove za lična primanja zaposlenih, a da pritom odnos finansijskog rezultata i prihoda ostane nepromijenjen. S obzirom na to da je regulatornim okvirom utvrđen model finansiranja domova zdravlja, a koji je prethodno opisan, nije moguće vršiti smanjivanje doznaka po navedenom osnovu, već je dato posmatranje rezultata korisno radi lakše interpretacije ušteda i analiziranja stepena značajnosti istih, za zdravstveni sistem Republike Srpske.

\section{REZULTATI ISTRAŽIVANJA}

Nakon što je vršeno testiranje više nezavisnih varijabli kao determinanti visine troškova ličnih primanja izraženih u procentima od prihoda, višestruka linearna regresija je pokazala da tri determinante: broj zaposlenih na 100 registrovanih lica (višak zaposlenih), visina prihoda po registrovanom licu (prihod doma zdravlja), visina ličnih primanja po zaposlenom, objašnjavaju zavisnu varijablu sa $87,31 \%$. P vrijednost za odsječak modela je na nivou od 0,20 , dok su parametri nagiba za sve tri varijable statistički značajni na nivou od 0,001. Vrijednosti koeficijenata uz 
broj zaposlenih i lična primanja po zaposlenom su pozitivnog predznaka, dok vrijednost koeficijenta uz prihod doma zdravlja ima negativnu vrijednost. Ovo je sasvim logično, jer što je veći broj zaposlenih, i što su prosječna lična primanja viša, viši je i nivo učešća troškova ličnih primanja u prihodu. A što su prihodi veći, manje je učešće troškova ličnih primanja u prihodu. Apsolutne vrijednosti koeficijenata dobijenih višestrukim regresionim modelom čije se ulazne vrijednosti standardizovani koeficijenti (z), koji stoje uz nezavisne varijable podijeljene sa njihovim zbirom, imaju sljedeće vrijednosti: prihod doma zdravlja - 35,05\%; broj zaposlenih - 47,77\%; lična primanja po radniku $-17,18 \%$. Ove relativne vrijednosti pokazuju intenzitet uticaja svake varijable na varijabilitet zavisne varijable. S obzirom na to da one sve zajedno objašnjavaju $87,31 \%$ ukupnog varijabiliteta, potrebno ih je pomnožiti sa ukupnim objašnjenim varijabilitetom. Tako pomnoženi parametri iznose: 30,6\%; 41,7\% i 15,0\%. Ovi parametri pokazuju procenat objašnjenosti varijabiliteta svake varijable. Tako možemo zaključiti da višak zaposlenih predstavlja najznačajniju determinantu visine ličnih primanja domova zdravlja. S obzirom na to da se troškovi ličnih primanja kreću od 37,3 do 109,4\% [8], ovo praktično znači da je višak zaposlenih najznačajniji uzročnik visokih troškova ličnih primanja.

Postojanje viška zaposlenih moguće je utvrditi jednostavnim poređenjem broja zaposlenih $\mathrm{u}$ domovima zdravlja sa brojem zaposlenih koji odgovara standardima i normativima. Međutim, standardi i normativi preuzeti su iz prakse razvijenih zemalja koje smatraju da ne postoji potreba za domovima zdravlja na područuju koje ima manje od 25.000 stanovnika. U Republici Srpskoj, 38 od 53 doma zdravlja organizovani su na područjima (jedna ili više opština) koja imaju manje od 25.000 stanovnika. Razlog je očigledan. Neke opštine su udaljene ili nedovoljno povezane putnom mrežom sa većim centrima, pa bi njihovo pripajanje većim centrima dovelo do narušavanja načela dostupnosti zdravstvene zaštite u Republici Srpskoj, i to u značajnoj mjeri. Imajući na umu sve što je naprijed izneseno, može se zaključiti da pomenutni normativi i standardi nisu primjenljivi na domove zdravlja u Republici Srpskoj. Tako bi domovi zdravlja, prema normativu, trebalo da zaposle nekog radnika na 1,7 radnih sati, a pritom u blizini ne postoji dom zdravlja u koji bi se takođe mogao zaposliti zdravstveni radnik kako bi popunio normu. Iz praktičnih i socijalnih razloga nije realno očekivati da se rukovodstvo doslovno drži normativa, te je često praksa da u takvim slučajevima zdravstveni radnik bude zaposlen na puno radno vrijeme i za to prima odgovarajuću neto platu. Očigledno je, dakle, da bi trebalo koristiti blaže kriterijume prilikom identifikacije viška zaposlenih, kod domova zdravlja sa manjim brojem registrovanih lica, upravo uzimajući u obzir nedjeljivost radnika u gore opisanom primjeru.

Ovaj problem prevaziđen je primjenom logaritamskog regresionog modela koji opisuje vezu između broja zaposlenih na 100 registrovanih lica (viška zaposlenih) i broja registrovanih lica. Dobijene vrijednosti po modelu predstavljaju gornju granicu tolerancije broja zaposlenih na 100 registrovanih lica. Ovako utvrđene granice predstavljaju relativne kriterijume, pri čemu oni zavise od broja registrovanih lica, broja zaposlenih na 100 registrovanih lica kod domova zdravlja sa sličnim brojem registrovanih lica.

$$
Y=0,0135058491-0,0008582051 \cdot \ln X)
$$

S obzirom na to da regresiona jednačina (4) pokazuje gornju granicu prihvatljivog broja zaposlenih na 100 registrovanih lica, preporučene vrijednosti za domove zdravlja, koje trenutno imaju više vrijednosti od modela, jednake su vrrijednostima dobijenih po modelu, dok se preporučuju stvarne vrijednosti za one domove zdravlja koje trenutno imaju niže vrijednosti od modela. Drugim riječima, vrijednosti po modelu su preporuka samo za one koji zapošljavaju više od modela. Primjenjujući ove preporuke, dolazimo do zaključka da nije neophodno smanjenje broja zaposlenih kod DZ Istočni Stari Grad, koji zapošljava 0,71 zaposlenog na 100 registrovanih lica. Istovremeno zaključujemo da je potrebno smanjenje broja zaposlenih u DZ Banja Luka, koji zapošljava 0,46 zaposlenih na 100 registrovanih lica. Ovaj zaključak, iako na prvi pogled nelogičan, proizilazi iz činjenice da DZ Istočni Stari Grad ima 871, a DZ Banja Luka ima 189.460 registrovanih lica [9]. Uvrštavajući broj registrovanih lica u logaritamski model (4) dobija se da su prihvatljive stope zaposlenosti za DZ Istočni Stari Grad i DZ Banja Luka na nivou od 0,74 i 0,26 , respektivno. $S$ obzirom na to da DZ Istočni Stari Grad trenutno zapošljava manje od relativnog kriterijuma $(0,71<0,74)$ njemu se ne preporučuje smanjenje broja zaposlenih, za razliku od DZ Banja Luka koji zapošljava više od relativnog kriterijuma $(0,46>0,26)$. Njemu se sugeriše značajno smanjenje broja zaposlenih.

Ako bi se preporučene vrijednosti primijenile u praksi, odnosno ako bi se smanjio broj zaposlenih u domovima zdravlja kod kojih je dijagnostifikovan višak zaposlenih, bile bi ostvarene izvjesne uštede. Ovako utvrđene uštede iznosile bi 11,2 miliona KM. Ova sredstva mogla bi biti iskorišćena za poboljšavanje finansijskog rezultata istih domova zdravlja kod kojih je dijagnostifikovan višak zaposlenih, ali i za podizanje kvaliteta zdravstvenih usluga nabavkom opreme, sanitetskog materijala, lijekova i sl. 


\section{ZAKLJUČAK}

Sprovedenim istraživanjem uz pomoć instrumentarija ekonometrijske analize utvrđeno je da su glavne determinante problema visokih troškova ličnih primanja, izraženih u procentu od prihoda doma zdravlja upravo: visok broj zaposlenih na 100 registrovanih lica (višak zaposlenih), nizak prihod (po registrovanom licu) i visoki troškovi ličnih primanja po zaposlenom. Ova veza ustanovljena je uz pomoć višestruke linearne regresione analize, na osnovu empirijskih podataka za 2015. godinu. Parametri nagiba u modelu, kao i cjelokupan model (F statistika), značajni su na nivou od 0,001. Prije uvršavanja podataka podaci za sve varijable standardizovane su uz pomoć standardizovanog odstupanja (Z). Nakon standardizovanja, dobijeni koeficijenti pokazuju relativan uticaj nezavisne varijable na zavisnu varijablu. Tako je ustanovljeno da je najznačajnija determinanta problema visokih troškova ličnih primanja upravko visok broj zaposlenih na 100 registrovanih lica (višak zaposlenih). Radi toga, dalje istraživanje je usmjereno ka preporukama za rješavanje ovog problema. Kako standardi i normativi nisu adekvatni zbog relativno male veličine domova zdravlja u Republici Srpskoj, preporučene vrijednosti ustanovljene su uz pomoć logaritamskog regresionog modela. Pridržavanjem preporučenih vrijednosti bile bi ostvarene uštede na nivou od 11,2 miliona KM.

Na ovaj način potvrđena je polazna hipoteza o glavnim determinantama ovog problema, te utvrđene preporuke za rješavanje problema i ublažavanja posljedica na finansijsko poslovanje domova zdravlja. Potrebno je istaći da se ne treba fokusirati samo na finansijske uštede na troškovima ličnih primanja, već da treba dati adekvatan značaj i efikasnosti zaposlenih u domovima zdravlja, čime bi se upotpunilo upravljanje ljudskim resursima u domovima zdravlja u Republici Srpskoj.

\section{LITERATURA}

[1] Zakon o zdravstvenoj zaštiti Republike Srpske, Službeni glasnik 109/09.

[2] Pravilnik o principima, uslovima i kriterijumima za zaključivanje ugovora sa davaocima zdravstvenih usluga u Republici Srpskoj u 2017. godini, Službeni glasnik 1/17.

[3] Pravilnik o osnovima standarda i normativa zdravstvene zaštite iz obaveznog zdravstvenog osiguranja, Službeni glasnik 83/11.

[4] R. Kelly, "Where can $\$ 700$ billion in waste be cut annually from the U.S. Healthcare System?", Thomson Reuters, October 2009.

[5] P. Smith, E. Mossialos, I. Papanicolas, "Performance measurement for health system improvement: experiences, challenges and prospects", World Health Organization, on behalf of the European Observatory on Health Systems and Policies 2008, 2008.

[6] I. Saint - Yves, "Staffing costs in primary health care", Journal of the Royal Society of Health, 104(3):108-10, 1984 Jun.

[7] Z. Mladenović, P. Petrović, "Uvod u ekonometriju", šesto izdanje, Ekonomski fakultet u Beogradu, Beograd.

[8] Finansijski izvještaji domova zdravlja Republike Srpske za 2015. Godinu

[9] Evidencija Fonda zdravstvenog osiguranja Republike Srpske. 


\title{
INEFFICIENCY DETERMINANTS - THE CASE OF HEALTH CENTRES' EMPLOYEES IN THE REPUBLIC OF SRPSKA
}

\begin{abstract}
:
In accordance with extension of life expectancy, decreasing of birthrate and growing problem of health care financing in Republic of Srpska, the issue of employees efficiency in health institutions is becoming more interesting. By observing 53 Community Health Centers in Republic of Srpska, it was noticed that employees cost share in revenue varies from $37.3 \%$ to $109.4 \%$, in 2015 , where unweighted average is $82.2 \%$. These results present challenge for of finding determinants of intensity and variability of employees inefficiency in Community Health Centers in Republic of Srpska. In the course of the research, data from financial statements of Community Health Centers and number of registered people in Community Health Centers were used as data source. Determining of determinants has been calculated by multiple linear regression, based on previously customized source data, converted in certain ratios. Analysis revealed that statistically, three determinants are significant, with total determined variability of $87.3 \%$ and those are: number of employees (47.1\%), payment by an employee (15\%) and revenue of Community Health Centers (30.6\%). Since the number of employees is the most important cause of inefficiency, the analysis is directed to determination of criteria for optimal number of employees. Optimal number of employees is determined by logarithmic regression analysis, where the number of registered people is independent variable. By reducing the number of employees to an optimal number, the fund of BAM 11.2 million would be released.
\end{abstract}

\section{Keywords:}

excess employees, optimal number of employees, realesed funds, multiple linear regression, simple logarithmic regression. 